\title{
Study of Maternal and Fetal Outcome in Pregnancy with Heart Disease
}

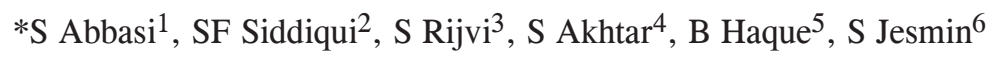

\begin{abstract}
Background: Heart disease complicating pregnancy is an important indirect cause of maternal mortality and morbidity. Maternal heart disease comprises .2\%-2\% of pregnancies and responsible for 10\%-20\% of maternal deaths ${ }^{1}$. Our study was done to evaluate fetomaternal outcomes in pregnancy with heart disease.

Objectives: Evaluation of fetomaternal outcome in pregnant patients with cardiac disease. Materials and Methods: This observational study was done in Bangabandhu Sheikh Mujib Medical University and Anwer Khan Modern Medical College Hospital among 51 pregnant women with known or newly diagnosed heart disease from January 2013-january 2015. Baseline data recorded demographic character, NYHA functional class, maternal complications, mode of delivery and neonatal outcome.

Results: Among 51 cardiac patients, 32 (63\%) were primigravida. Mostly 46 (90.6\%) belonging to NYHA Class I and II. Rheumatic heart disease seen in $45(87 \%)$ and congenital heart disease in $10 \%$ subjects. Mitral stenosis was the most common, seen in $22(41 \%)$ cases. $47.33 \%$ patients were delivered vaginally and LSCS done in $41 \%$ patients. The fetal outcome were live births in (96.6\%) cases, $(27.4 \%)$ babies required NICU admission.

Conclusion: An improvement in modern techniques of monitoring, better understanding of pathophysiology of cardiac disease and multi disciplinary care can lead to substantial improvement in the feto maternal outcome.
\end{abstract}

Key Words: Pregnancy, Cardiac disease, RHD, NYHA Classification

\section{Introduction}

Pregnancy makes a significant demand on the cardiovascular system. Cardiac disease in the pregnant woman can present a challenge to the obstetrician, cardiologist and neonatologist ${ }^{1}$. The spectrum of cardiovascular disease is changing and varies between countries ${ }^{2}$. At present $0.2-2 \%$ of all pregnancies are complicated by cardiovascular disease $^{3}$. Cardiac disorders contribute to approximately $20.5 \%$ of maternal deaths ${ }^{4}$. The ratio of RHD and CHD is decreasing due to improved pediatric care and improved surgical interventions early in childhood. Increasing number of women with cardiac disease is reaching the reproductive age due to modern therapeutic options and moreover these patients are now attempting pregnancy multiple times due to improved availability of life saving modern therapy ${ }^{7}$. Maternal functional status is a most important predictor of outcome and most

$1 *$ Dr. Sharmin Abbasi, Assistant Professor, Dept of Obstetrics and Gynecology, Anwer Khan Modern Medical College Hospital

${ }^{2}$ Prof. Sehereen Farhad Siddiqua, Professor \& Head, Dept of Obstetrics and Gynecology, Anwer Khan Modern Medical College Hospital

${ }^{3}$ Dr. Shifin Rijvi, Registrar Dept of Obstetrics and Gynecology, Anwer Khan Modern Medical College Hospital

${ }^{4}$ Dr. Salma Akhtar, Registrar Dept of Obstetrics and Gynecology, Anwer Khan Modern Medical College Hospital

${ }^{5}$ Dr Benozir haque, Registrar Dept of Obstetrics and Gynecology, Anwer Khan Modern Medical College Hospital

${ }^{6}$ Dr. Suha Jesmin, Associate Professor, Dept of Obstetrics and Gynecology, Anwer Khan Modern Medical College Hospital

*Corresponding Author

Date of submission: 24.03.2017, Date of acceptance: 16.05.2017

AKMMC J 2017; 8(2) : 112-116 
often defined by NYHA functional class ${ }^{6}$. Poor functional status and cyanosis are mostly associated with adverse maternal and neonatal outcome ${ }^{7}$. In developing countries, anemia is a major associated factor that precipitates heart failure. Pregnant women with cardiac disease fall into two categories.Those with diagnosed heart disease and under treatment even before becoming pregnant. Those with previously undiagnosed heart disease Cardiac lesions and pregnancy both may affect each other adversely. It is essential to thoroughly evaluate patients for underlying cardiovascular disease in order to promote optimal care during pregnancy that plays a major role in the outcome ${ }^{8}$.

Joint care of obstetrician, cardiologist anesthetist and neonatologist, avoidance of complications that add to the burden on the heart and compliance of the patient and her family to regular follow up will go a long way in ensuring a safe outcome for mother and fetus.

\section{Materials and Methods}

This Observational study was done in Bangabandhu Sheikh Mujib Medical University and Anwer Khan Modern Hospital among 51 pregnant women with known or newly diagnosed heart disease from January 2013-january 2015. The diagnosis was confirmed by relevant investigations like ECG, Echocardiography, if Chest X-ray needed then abdominal shield was used. These included booked antenatal cases and unbooked emergency cases. The patients were regularly seen at the antenatal clinic and were also seen regularly by cardiologist. The data were obtained from review of medical records. Baseline data recorded including age, parity, gestational age, type of lesion, duration of disease, time of diagnosis, treatment history, New York heart association (NYHA) functional class, maternal complications, mode of delivery and indication of caesarean section, neonatal outcome recorded in term of APGAR score at 1 and 5 minutes, birth weight, maturity ( $>37$ weeks) and admission to NICU were noted. In case of maternal mortality the cause of death was noted. Patients were assessed for the mode of delivery those without any contraindications were allowed spontaneous vaginal delivery while others had cesarean section. Fluid overload and ergometrine were avoided. Prophylactic antibiotic was given to patients. Low molecular weight heparin (LMWH) was given to those with prosthetic valve replacement. Digoxin and diuretics were given in some patients. Patients were kept under strict follow up for at least 48 hours post operative period. A search was made for symptoms and signs of infections anywhere in the body, such as chest, urinary tract and cervico vaginal infections and if found, these were vigorously treated. Patients were advised on the importance of taking adequate rest. They were given Iron and Folate supplements and discharged after 10 days with proper postnatal advice.

\section{Results}

Among 51 cardiac patients $38(74.5 \%)$ were of 20 30 years of age, $32(62.7 \%)$ were primigravida. $80.39 \%$ patients were in regular antenatal care and $62.7 \%$ were diagnosed as cardiac patient before pregnancy and $37.3 \%$ were diagnose after pregnancy. $62.7 \%$ patients residence from rural area and $37.3 \%$ from urban area. $90.2 \%$ were house wife and $9.8 \%$ were service holder. $54.09 \%$ patients completed their primary education and $25.49 \%$ passed secondary education or more. Rheumatic heart disease seen in $44(86.3 \%)$ and congenital heart disease in $9.8 \%$ subjects. 2 patients (3.9\%) suffered from peripartum cardiomyopathy. Among RHD Mitral stenosis was the most common, seen in $21(41.2 \%)$ cases. Mitral regurgitation in 9.8\% cases, mitral stenosis and regurgitation in $17.6 \%$ patients and mitral regurgitation and aortic regurgitation in $11.8 \%$ cases. In congenital heart disease most common lesions was ASD (5.9\%). Common presentations of the patients were breathlessness (41.2\%) and palpitation (27.5\%), others symptoms included cough (13.7\%), generalized weakness (11.8\%), leg edema (5.9\%). Mostly 45 (88.2\%) belonging to New York Heart Association (NYHA) Class I and II, 9.8\% were in class III and $2 \%$ were in class IV. Common maternal obstetrical complications were anemia (47.1\%) and preeclampsia (21.6\%) and others were hypothyroidism $(5.9 \%)$, placenta previa $(3.9 \%)$, breech (2\%) twin pregnancy (2\%) APH (2\%), PPH 
in $3.9 \%$ patients. Regarding cardiac complications, congestive cardiac failure complicated (17.9\%) case, atrial fibrillation in $3.9 \%$ cases, pulmonary edema $5.9 \%$ case and pulmonary atrial hypertension in $2 \%$ cases. Among them $86.3 \%$ were more than 37 weeks gestational ages at the time of delivery. $47.1 \%$ patients were delivered vaginally and LSCS done in $41.2 \%$ patients, $5.9 \%$ patients delivered by forceps, $3.9 \%$ delivered by ventouse and assisted breech was done in $2 \%$ cases. Overall maternal outcome showed $76.5 \%$ patients were discharged with advised, $9.8 \%$ needed CCU, 5.9\% were referred to ICU and maternal mortality was in 2 cases. The fetal outcomes among them were live births in $(98 \%)$ cases, $(25.5 \%)$ babies required NICU admission and Perinatal mortality was 2 cases.

Table 1: Demographic Character of patient

\begin{tabular}{|c|c|c|}
\hline Parameter & Number (51) & Percentage (\%) \\
\hline \multicolumn{3}{|l|}{ Age } \\
\hline$<20$ & 9 & $17.6 \%$ \\
\hline $20-30$ & 38 & $74.5 \%$ \\
\hline$>30$ & 4 & $7.8 \%$ \\
\hline \multicolumn{3}{|l|}{ Gravida } \\
\hline Primi & 32 & $62.7 \%$ \\
\hline Gravida 2 & 13 & $25.6 \%$ \\
\hline Gravida 3 or more & 6 & $11.8 \%$ \\
\hline \multicolumn{3}{|l|}{ ANC } \\
\hline Regular & 17 & $33.3 \%$ \\
\hline Irregular & 24 & $47.1 \%$ \\
\hline No & 10 & $19.6 \%$ \\
\hline \multicolumn{3}{|l|}{ Time of Diagnosis } \\
\hline Before pregnancy & 32 & $62.7 \%$ \\
\hline After Pregnancy & 19 & $37.3 \%$ \\
\hline \multicolumn{3}{|c|}{ Gestational age at deliver } \\
\hline Term & 44 & $86.3 \%$ \\
\hline Preterm & 7 & $13.7 \%$ \\
\hline \multicolumn{3}{|l|}{ Occupation } \\
\hline House wife & 46 & $90.2 \%$ \\
\hline Service Holder & 5 & $9.8 \%$ \\
\hline \multicolumn{3}{|l|}{ Residence } \\
\hline Urban & 19 & $37.3 \%$ \\
\hline Rural & 32 & $62.7 \%$ \\
\hline
\end{tabular}

Table 2: Types of heart disease among study population

\begin{tabular}{|c|c|c|c|}
\hline \multicolumn{2}{|c|}{ Parameter } & Number (51) & Percentage (\%) \\
\hline \multicolumn{2}{|c|}{ Rhematic Heart Disease } & 44 & 86.3 \\
\hline \multicolumn{2}{|c|}{ Mitral stenosis } & 21 & 41.2 \\
\hline \multicolumn{2}{|c|}{ Mitral Regurgitation } & 5 & 9.8 \\
\hline \multicolumn{2}{|c|}{ Mitral Stenosis + Mitral Regurgitation } & 9 & 17.6 \\
\hline \multicolumn{2}{|c|}{ Aortic Stenosis + Aortic Regurgitation } & 2 & 3.9 \\
\hline \multicolumn{2}{|c|}{ Mitral Regurgitation + Aortic Regurgitation } & 6 & 11.8 \\
\hline \multicolumn{2}{|c|}{$\begin{array}{l}\text { Mitral stenosis + Tricuspid regurgitation }+ \\
\text { Pulmonary Regurgitation }\end{array}$} & 2 & 3.9 \\
\hline \multicolumn{2}{|c|}{ Mitral stenosis + Pulmonary Hypertension } & 1 & 2.0 \\
\hline \multicolumn{2}{|c|}{ Congenital } & 5 & 9.8 \\
\hline \multicolumn{2}{|l|}{ ASD } & 3 & 5.9 \\
\hline \multicolumn{2}{|l|}{ VSD } & 1 & 2.0 \\
\hline \multicolumn{2}{|l|}{ MVP } & 1 & 2.0 \\
\hline \multicolumn{2}{|c|}{ Peripartum cardiomyopath } & 2 & 3.9 \\
\hline \multicolumn{4}{|c|}{ 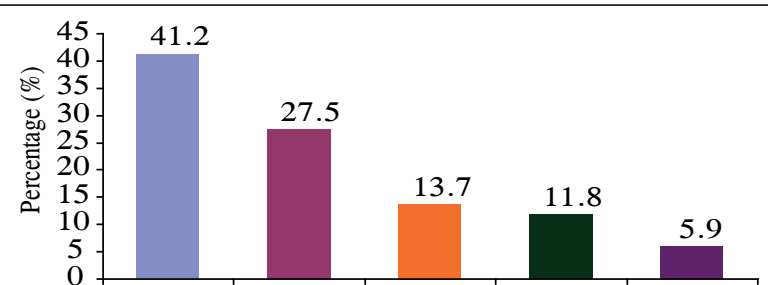 } \\
\hline & $\begin{array}{l}\text { athlessness } \\
\text { Palpitation Cough } \\
\text { Clinical presentat }\end{array}$ & $\begin{array}{l}\text { General } \\
\text { weakness } \\
\text { tion }\end{array}$ & 1 Leg edema \\
\hline
\end{tabular}

Fig. 1: Clinical presentation of the study patients

Table 3: Functional class of cardiac disease on NYHA classification

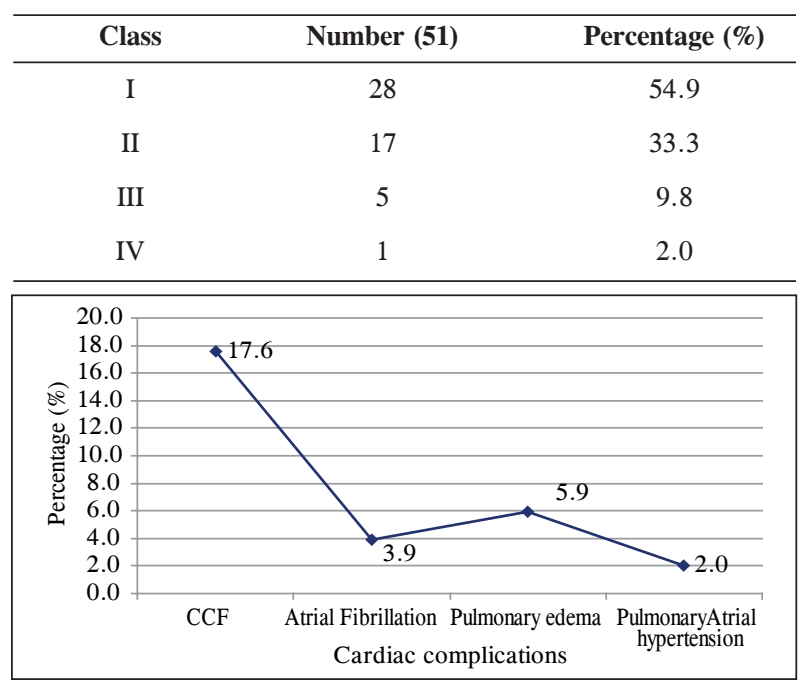

Fig. 2: Cardiac complication of the mother 
Table 4: Overall maternal outcome

\begin{tabular}{lcc}
\hline Outcome & Number (51) & Percentage (\%) \\
\hline Normal Labour & 24 & 47.1 \\
Cesarean Section & 21 & 41.2 \\
Discharge with advised & 39 & 76.5 \\
Referred to CCU & 5 & 9.8 \\
Referred to ICU & 3 & 5.9 \\
Mortality & 4 & 7.8 \\
\hline
\end{tabular}

Table 5: Causative leison of maternal death

\begin{tabular}{ll}
\hline Causative leison & Maternal death \\
\hline MS with AS & 1 \\
MS with MR & 1 \\
Primary pulmonary Hypertension & 2 \\
\hline
\end{tabular}

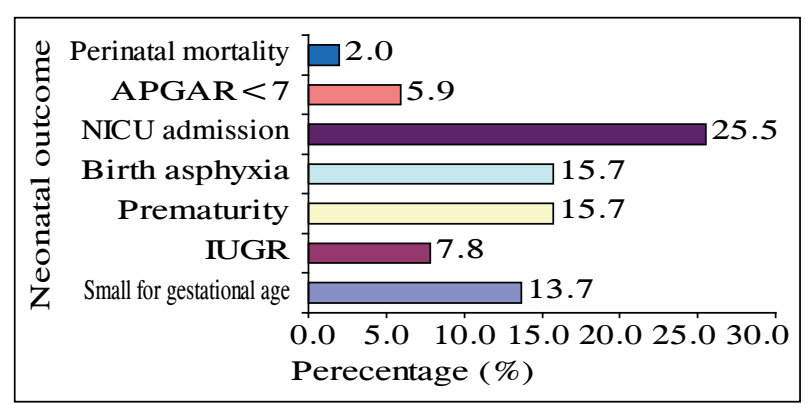

Fig. 3: Neonatal outcome of the study subject

\section{Discussion}

In the present study, we determined the type of cardiac lesion and assessed the fetomaternal outcome in pregnant women with cardiac disease. Cardiac disease continues to be a risk factor for maternal and neonatal mortality and morbidity9 Most of them were primigravida (62.7\%) and $(80.39 \%)$ were booked cases. The study by Sheela et al, showed similar type of result. 10

Majority of the patients (88.2\%) were in NYHA class I and II. Similar findings were seen in other studies $^{11,12}$. Hsieh et al in their study reported that out of the total feto maternal deaths $75 \%$ were in patients with NYHA class III and IV $^{13}$. In our study, predominant lesion was rheumatic heart disease $(86.3 \%)$, MS being the most common $(41.2 \%)$. Similar results were noted in the studies by Mahesh et al (44.6\%) and by Nilajkumar et al $(55 \%)^{14,15}$. Congenital heart disease accounted for
9.8\% of cases, among which ASD was most common $(5.9 \%)$. Similar results were seen in studies by Sheela et al and Nilajkumar et al ${ }^{15}$. In our study, $47.1 \%$ women had spontaneous vaginal delivery. The Caesarean section was performed in $41.2 \%$ cases mostly for obstetrical indications. The second stage was cut short by instrumentation in $9.8 \%$ of patients.

Majority of cases were associated with anemia (47.1\%) followed by preeclampsia $(21.6 \%)$ that worsened the underlying cardiac lesion during pregnancy. Thus, the early diagnosis and treatment of complications as anemia and preeclampsia can improve the outcome. Studies done by various authors have shown similar results ${ }^{16,17}$.

The cardiac complications were noted in 15 (29.4\%) patients out of which 9 (17.6\%) developed congestive cardiac failure, 2 developed atrial fibrillation and another 3 had pulmonary edema. Overall maternal outcome showed $76.5 \%$ patients were discharged with advised, $9.8 \%$ needed CCU, $5.9 \%$ were referred to ICU and maternal mortality was in 2cases. Similar finding were seen in studies done by Mahesh et al ${ }^{18,19}$.

The small for gestation age was seen in $7(13.7 \%)$ babies. Total $13(25.5 \%)$ babies were admitted to NICU. The perinatal mortality was $2 \%$ in our study. The results were comparable to the studies done by Mahesh et al, Hanania et al and Suri at $\mathrm{al}^{20,21}$. Despite the potential for significant maternal morbidity in most patients with cardiac disease, satisfactory outcome can be expected with careful antenatal, intrapartum and postpartum management.

\section{Conclusion}

Heart disease in pregnancy has a major impact on pregnancy outcome. Rheumatic heart disease being the prominent cardiac lesion. An improvement in modern techniques of monitoring, better understanding of pathophysiology of cardiac disease and multi disciplinary care can lead to substantial improvement in the feto maternal outcome and can reduce maternal and fetal mortality and morbidity. 
Conflict of interest: We have no conflict of interest.

\section{References}

1. Burlingame $\mathrm{J}$, Horiuchi B. The contribution of heart disease to pregnancy-related mortality according to the pregnancy mortality surveillance system. J Perinatal. 2012; 32: 163-9.

2. Surge D, Blake S. Pregnancy complicated by maternal heart disease at the National maternity Hospital, Dublin 1969-1978. Am J Obst Gyne. 1981; 139(1): 1-6.

3. Barbosa PJ, Lopes AA,. Prognostic factors of rheumatic mitral stenosis during pregnancy and puerperium. Arq Bras Cardiol. 2000; 75: 215-24.

4. Sawhney H, Aggarwal N, Grover A. Maternal and perinatal outcome in rheumatic heart disease. Int J Gynaecology Obstet. 2003; 80: 9-14.

5. Cunningham FG, Leveno KJ. Cardiovascular Disease In Williams Obstetrics. 24 $4^{\text {th }}$ edition. McGraw Hill Education; New York; 2010.

6. James, Steer,High risk pregnancy management option. In Cardiac disease in pregnancy. 4th edition: 2012; 627-656.

7. Bhatla, Yadav, Mishra. The cardiac case. In Ian Donald's practical obstetrics problems. 6th edition. BI Publications Pvt Ltd. India. 2010; 103-126.

8. Davies GA, Herbert WN. Assessment and management of cardiac disease in pregnancy. $\mathrm{J}$ Obstet Gynaecol. 2007; 29(4): 331-6.

9. Ohana P, Onaka A, Sauvage LM. The contribution of heart disease to pregnancyrelated mortality according to the pregnancy mortality surveillance system. J Perinatal. 2012; 32: 163-9.

10. Sheela CN, Karanth S, Patil CB. Maternal cardiac complications in women with cardiac disease in pregnancy. Int. J Pharma Biomed Res. 2011; 2(4), 261-5.
11. Koregeol M, Nina, Nayak R, Amritha. Maternal and perinatal outcomes of pregnancies complicated by cardiac disease. J Turkish German Gynaecol Assoc. 2009; 10: 30-4.

12. Vasu S, Stergiopoulos K. Valvular heart disease in pregnancy. Hellenic J Cardiol. 2009; 50: 498-510.

13. Hsieh TT, Chen KC, Soong JH. Outcome of pregnancy in patients with organic heart disease in Taiwan. Asia Oceania J Obstet Gynaecol 2007; 19: 21-7

14. Bhatla N, Lal S, Behra G, Kriplani A, et al. Cardiac Disease in pregnancy. Int J Gynaecol Obstet. 2003; 82: 153-9.

15. Kovavisarach E, Nuaplot P. Outcome of pregnancy among parturients complicated with heart disease in Rajavithi hospital. J Med Assoc Thai. 2007; 90: 2253

16. Surge D, Blake S, Donald D. Pregnancy complicated by maternal heart disease at the National maternity Hospital, Dublin 19691978. Am J Obst Gyne. 1981; 139(1): 1-6.

17. Barbosa PJ, Lopes AA, Feitosa GS. Prognostic factors of rheumatic mitral stenosis during pregnancy and puerperium. Arq Bras Cardiol. 2000; 75: 215-24.

18. Sawhney H, Aggarwal N, Suri V. Maternal and perinatal outcome in rheumatic heart disease. Int J Gynaecology Obstet. 2003; 80: 9-14.

19. Sheela CN, Karanth S, Patil CB. Maternal cardiac complications in women with cardiac disease in pregnancy. Int. J Pharma Biomed Res. 2011; 2(4), 261-5.

20. Koregeol M, Nina, Nayak R, Amritha. Maternal and perinatal outcomes of pregnancies complicated by cardiac disease. J Turkish German Gynaecol Assoc. 2009; 10: 30-4.

21. Vasu S, Stergiopoulos K. Valvular heart disease in pregnancy. Hellenic J Cardiol. 2009; 50: 498-510. 